\title{
CONTRIBUIÇÃO DA EXTENSÃO PARA UMA DOCÊNCIA UNIVERSITÁRIA INOVADORA: UM ESTUDO A PARTIR DO PROGRAMA DE LIGAS DA ENFERMAGEM DA UNIVERSIDADE ESTADUAL VALE DO ACARAÚ
}

\author{
CONTRIBUCIÓN DE LA EXTENSIÓN A UNA INNOVADORA ENSEÑANZA \\ UNIVERSITARIA: UN ESTUDIO DEL PROGRAMA LIGA DE ENFERMERÍA DE LA \\ UNIVERSIDADE ESTADUAL VALE DO ACARAÚ
}

CONTRIBUTION OF EXTENSION TO AN INNOVATIVE UNIVERSITY TEACHING: A STUDY FROM THE NURSING LEAGUE PROGRAM OF VALE DO ACARAÚ STATE UNIVERSITY

\author{
Rejane Maria Gomes da SILVA ${ }^{1}$ \\ Adriana CAMPANI ${ }^{2}$ \\ Jaqueline Gomes NEGREIROS ${ }^{3}$
}

RESUMO: Nossos estudos têm demonstrado que, mais do que novas tecnologias da informação/comunicação e metodologias ativas de ensino-aprendizagem, a inovação pedagógica na universidade requer rupturas epistemológicas na construção e na relação com o conhecimento científico. Esse processo passa pela experiência intercultural reinventiva sustentada por uma epistemologia socialmente construída desenhada e corporificada por um currículo includente/inclusivo. A dimensão reiventiva desse processo desafia a docência universitária a cumprir um papel importante de mediação, rupturas e práticas reinventivas nos processos formativos. Para ampliar essa discussão, o presente artigo objetiva apresentar uma análise sobre a contribuição da extensão universitária para docência inovadora a partir de uma pesquisa que realizamos com professoras coordenadoras do Programa de Extensão ligas de enfermagem da Universidade Estadual Vale do Acaraú. Considerando a extensão universitária um caminho teórico-metodológico de produção de conhecimento por meio da experiência que possibilita a interface dos saberes da cultura acadêmica e das que integram a universidade, essa pesquisa, em sua primeira etapa de análise, identificou que a experiência de extensão contribui para um processo inovador na docência universitária porque estimula a produção do conhecimento com responsabilidade social; desafia a criar estratégias pedagógicas para incluir expectativas, descobertas e experiências dos alunos; dinamiza o planejamento das aulas; exercita e qualifica a escuta e fortalece as incertezas, desafiando, assim, a docência universitária a se reinventar numa condição mediadora para $\mathrm{o}$ fortalecimento $\mathrm{da}$ interculturalidade e inclusão de saberes.

PALAVRAS-CHAVE: Extensão universitária. Inovação pedagógica. Docência universitária.

\footnotetext{
${ }^{1}$ Universidade Estadual Vale do Acaraú (UVA), Sobral - CE - Brasil. Professora do Curso de Pedagogia da UVA. Membro do OIIIPE. ORCID: https://orcid.org/0000-0003-2215-0686. E-mail: rejanemgs@gmail.com

${ }^{2}$ Universidade Estadual Vale do Acaraú (UVA), Sobral - CE - Brasil. Professora do Curso de Pedagogia da UVA. Membro do OIIIPE. ORCID: https://orcid.org/0000-0002-4524-7694. E-mail: campaniadriana@gmail.com

${ }^{3}$ Universidade Estadual Vale do Acaraú (UVA), Sobral - CE - Brasil. Professora do Curso de Geografia da UVA. Membro do OIIIPE. ORCID: https://orcid.org/0000-0003-3119-4509. E-mail: jaque.negreiros@hotmail.com
} 
RESUMEN: Nuestros estudios (CAMPANI; SILVA; PARENTE, 2018; CUNHA, 2005; SANTOS, 2008) han demostrado que, más que las nuevas tecnologías de información/comunicación y metodologías activas de enseñanza-aprendizaje, la innovación pedagógica en la universidad requiere rupturas epistemológicas en la construcción y en la relación con el conocimiento científico. Este proceso pasa por la experiencia intercultural inventiva sustentada por una epistemología socialmente construida, diseñada y encarnada por un plan de estudios que incluye/inclusivo (POPKEWITZ, 1997; HALL, 2001). La dimensión inventiva de este proceso desafía a la enseñanza universitaria a cumplir un papel importante de mediación, interrupción y reinvención de prácticas en los procesos formativos. Para ampliar esta discusión, este artículo tiene como objetivo presentar un análisis de la contribución de la extensión universitaria a la enseñanza innovadora a partir de una investigación que realizamos con el grupo de maestras coordinadoras del Programa de extensión ligas de enfermería de la Universidade Estadual Vale do Acaraú. Considerando la extensión universitaria un camino teórico-metodológico de producción de conocimiento a través de la experiencia que permite la interfaz de los saberes de la cultura académica y de las que integran la universidad (BONDIA, 2002; SANTOS, 2000), esta investigación, en su primera etapa de análisis, identificó que la experiencia de extensión contribuye a un proceso innovador en la enseñanza universitaria porque estimula la producción de conocimiento con responsabilidad social; desafía a crear estrategias pedagógicas para incluir expectativas; descubrimientos y experiencias de estudiantes; dinamiza el plan de las clases; ejercita y califica la escucha y fortalece las incertidumbres, desafiando asi la enseñanza universitaria para reinventarse como mediadora para el fortalecimiento de la interculturalidad y la inclusión de los saberes.

PALABRAS CLAVE: Extensión universitaria. Innovación pedagógica. Enseñanza universitaria.

ABSTRACT: Our studies (CAMPANI; SILVA; PARENTE, 2018; CUNHA, 2005; SANTOS, 2008) have shown that, more than new information/communication technologies and active teaching-learning methodologies, pedagogical innovation in universities requires epistemological disruptions in construction and in relation to scientific knowledge. This process goes through reinventing intercultural experience sustained by a constructed epistemology designed and socially embodied by an extensive/inclusive curriculum (POPKEWITZ, 1997; HALL, 2001). The reinventing dimension of this process challenges university teaching to fulfill an important role of mediation, disruption and reinventing practices in formative processes. To broaden this discussion, this article aims to present an analysis of the contribution of university extension to innovative teaching from a research that we conducted with the group of coordinating teachers of the Nursing Extension Program at State University Vale do Acaraú. Considering the university extension a theoreticalmethodological way of knowledge production through the experience that allows the interface of the knowledge of the academic culture and the ones that integrate the university (BONDIA, 2002; SANTOS, 2000), this research, in its first analysis stage, identified that the extension experience contributes to an innovative process in university teaching because it stimulates the production of knowledge with social responsibility; challenges to create pedagogical strategies to include expectations; student discoveries and experiences; streamlines lesson planning; exercises and qualifies the listening and strengthens uncertainties, thus challenging 
university teaching to reinvent itself as a mediator for the strengthening of interculturality and inclusion of knowledge.

KEYWORDS: University extension. Pedagogical innovation. University teaching.

\section{Introdução}

A extensão tem sido discutida no âmbito universitário como uma forte premissa para o fortalecimento da pedagogia universitária, bem como para oportunizar a inovação pedagógica. Sendo assim, tem sido vista como um processo educativo, cultural e científico que vem articular o ensino e a pesquisa numa relação indissociável, transformando a relação entre universidade e sociedade.

As discussões acerca da indissociabilidade entre o ensino, pesquisa e extensão na universidade acenam sobre a importância e possibilidade de refletirmos sobre o que se iniciou de forma separada. Neste sentido, a extensão universitária seria um espaço institucional da interdisciplinaridade, que acolhe a transversalidade ao unir as diferentes áreas do conhecimento, pela possibilidade de responder aos desafios a ela impostos e de multiplicar os espaços de diálogo entre a teoria-prática, por meio da multiplicação dos espaços de ensinar e aprender.

Consideramos a Extensão Universitária a chave para um novo modelo de formação discente; uma via de mão dupla, baseada na interface de conhecimentos teóricos, práticos, culturais e cotidianos, que ultrapassam muros das instituições de ensino superior, onde encontramos nela a possibilidade de multiplicar e disseminar a vida universitária na sua forma única de lidar e operar com o conhecimento científico, o que torna possível a inclusão da sociedade no processo reflexivo da universidade. Neste sentido defendemos ser a Extensão Universitária o locus privilegiado para a produção de conhecimento (re)emancipatório (SANTOS; ALMEIDA FILHO, 2008), constituindo-se em um dos caminhos para a construção de uma universidade mais aberta, ética, solidária e que possibilite a educação ser pensada de forma mais transgressora e autônoma.

A universidade tem um papel fundamental na superação das muitas questões sociais que tem adoecido e até mesmo enfraquecido as pessoas enquanto sociedade. Ela tem sido desafiada no enfrentamento de enfermidade que assolam as comunidades, principalmente as periféricas, desatendidas quase que totalmente pelo Estado. 
A extensão universitária contribui com a inovação pedagógica pelo processo de mediação de construção do conhecimento transversal entre teoria e prática, promovendo a integração entre a universidade e a sociedade, abrindo horizontes para um conhecimento mais criativo e inovador, fortalecendo uma aprendizagem mais compreensiva, significativa, autônoma, reflexiva, produtiva, interdisciplinar, complexa e dialógica, provocando o protagonismo no processo de aprendizagem.

Imbernón (2000) contribui com reflexões relevantes para se pensar a inovação na educação superior, ressaltando quatro ideias-força na base da mudança para projetar a educação visando o futuro promissor:

A recuperação por parte dos professores e demais agentes educativos do controle sobre seu processo de trabalho; a valorização do conhecimento, tanto daquele já adquirido e desenvolvido pelas gerações e culturas anteriores, que tem seu valor e importância mesmo nos dias de hoje, quanto dos novos conhecimentos que são investigados e produzidos atualmente em novas condições de número de informações, de velocidade de comunicação e de proliferação de fontes de conhecimento; a valorização da comunidade como verdadeira integrante do processo educativo, da comunidade de aprendizagem, co-responsável pelo projeto pedagógico da instituição; a diversidade como projeto cultural e educativo (IMBERNÓN, 2000, p. 80).

Reforça-se o papel do professor como educador responsável pela mediação pedagógica, que estimule a aprendizagem do aluno como processo pessoal e grupal, oriente seus trabalhos e discuta com ele suas dúvidas, seus problemas, incentivando a avançar no processo do conhecimento. $\mathrm{O}$ estudante universitário protagonista do processo de aprendizagem, o que altera radicalmente a prática tradicional de se entregar todas as informações já prontas e sistematizadas pelo professor para memorização e reprodução. $\mathrm{O}$ sentido da mudança trazida por Imbernón (2000) corrobora com a perspectiva de Cunha (2010, p. 23), quando compreende inovação como uma "ruptura necessária que permita reconfigurar o conhecimento para além das regularidades propostas pela modernidade [...], pois, uma ruptura paradigmática e não apenas a inclusão de novidades, inclusive as tecnológicas".

Compreendemos que a formação na universidade requer práticas formativas inovadoras. Tais práticas são aqui compreendidas como aquelas que rompem com o paradigma da racionalidade técnica, baseado, entre outros aspectos, em lógica disciplinar e na transmissão de conhecimentos científicos.

As práticas formativas inovadoras requerem inovação curricular na universidade. Um currículo que reconheça as diferenças, o desenvolvimento de posturas investigativas, o 
fortalecimento dos saberes mediante a participação ativa dos estudantes universitários, a legitimidade do currículo pluriversitário (SANTOS, 2011).

O currículo pluriversitário se alimenta da ecologia de saberes, sustentada, essencialmente, nas práticas extensionistas emancipatórias da universidade. As práticas extensionistas numa perspectiva emancipatória reconhecem que o simples direito à diferença entre as diversas culturas é insuficiente, é preciso estar a favor das transformações. Nesse caso busca-se uma extensão invertida (SANTOS, 2011), ou seja, a universidade sendo epistemologicamente contaminada pela sociedade em um processo de partilha e troca de experiências.

A docência universitária inovadora reconfigura saberes ao reconhecer outras formas de produção dos mesmos, não ignora a dimensão sócio-histórica do conhecimento; constrói redes de aprendizagem fortalecendo a dimensão complexa do conhecimento, gesta os atos pedagógicos com ações participativas e democráticas para uma pedagogia includente, intercultural, se coloca na condição de mediadora dos processos de aprendizagem.

Nessa condição, reivindica-se uma docência protagonista nos processos criativos da sua prática, respeitando e reconhecendo outras autorias na perspectiva da produção do conhecimento. A docência inovadora está sempre aberta a novos olhares, novas direções, novas perspectivas. Para isso ela tem que lidar com o desafio permanente da recriação, da reinvenção, da relocação, do reencontro, da retomada, da repartida.

A Política de Extensão da universidade, de acordo com o Plano Organizacional, é orientada para "decodificação do saber acadêmico"; "entrega à comunidade dos resultados de suas pesquisas e saberes"; "ênfase na extensão cultural" e "permanente sintonia com a comunidade para a oferta de treinamento e serviços" (PLANO ORGANIZACIONAL; UVA, 2008, p. 22). Neste sentido a extensão na UVA é organizada em atividades acadêmicas identificadas de acordo com seus fins, buscando fortalecer a relação entre ela e a sociedade, que, por consequência, busca contribuir para a elevação da qualidade da educação.

Desta forma, segundo o estabelecido no Plano Organizacional (2008), a extensão na UVA visa desenvolver o pensamento social que, aliado ao seu corpo discente, busca interligar as atividades de ensino e pesquisa com as demandas da sociedade, procurando assim assegurar o compromisso social da universidade. A extensão atua como elo entre universidade e sociedade, constituindo-se num elemento indispensável na efetivação da relação teoriaprática, onde a relação ensino e extensão acenam para transformações significativas no processo de ensino, onde alunos e professores constituem-se em sujeitos do ato de aprender, 
possibilitando assim a socialização e democratização do saber acadêmico através do intercâmbio entre a academia e as comunidades.

Até o presente momento, nosso estudo tem identificado que na Universidade Estadual Vale do Acaraú - UVA, locus do estudo, a extensão é formalmente concebida como um "processo interdisciplinar, educativo, cultural, científico e político que promovem a interação transformadora entre a Universidade e a sociedade" (Resolução CEPE/UVA 27/2018). Ainda não identificamos esse princípio de forma clara nos documentos dos cadastros que descrevem os objetivos das ações extensionistas. No entanto, o desenvolvimento das ações em forma de projeto apresenta elementos que retratam princípios além dos que identificamos nos seus objetivos. Estamos na fase de conhecer melhor esses elementos.

Desde 2017 que a universidade vem debatendo a curricularização da extensão. A Resolução CEPE/UVA 27/2018 é fruto desse debate. A partir dela formou-se um comitê da extensão, com representantes de cada curso de graduação. O objetivo maior desse comitê é construir uma política de extensão institucional que possa viabilizar formas de curricularizar a extensão, integrar a universidade com a comunidade e articular a extensão com o ensino e a pesquisa.

Essas ações têm possibilitado reflexões sobre o papel da extensão, bem como sua ressignificação na IES, tendo em vista que ainda não percebemos nas discussões e também nas ações extensionistas desenvolvidas uma clareza com relação à concepção de extensão, como também de uma política que mostre os caminhos por onde a instituição pretende trilhar para ela, principalmente neste cenário atual com o processo de curricularização, onde os Projetos Político Pedagógicos dos Cursos vão ter que inserir $10 \%$ do componente extensão em sua matriz, conforme a meta 12 do Plano Nacional de Educação(2014) e as Diretrizes Curriculares para a Extensão Universitária aprovada em dezembro de 2018.

Nossos estudos (CAMPANI; SILVA; PARENTE, 2018) e (SILVA; CAMPANI; PARENTE, 2018) vem reafirmando a concepção de que na extensão universitária existem caminhos profícuos para inovação pedagógica na universidade e tudo que dela demanda como a inovação curricular, inovação na docência e inovação na gestão dos processos. Nessa perspectiva, iniciamos uma pesquisa intitulada: Extensão universitária na Universidade Estadual Vale do Acaraú: experiências de inclusão, interculturalidade e inovação pedagógica, cujo objetivo é analisar ações extensionistas da Universidade Estadual Vale do Acaraú, no período de 2015 a 2016, que apresentam experiências de inclusão social, interculturalidade e inovação pedagógica na universidade. Na primeira etapa dessa pesquisa, foi possível compreender que a extensão estabelece uma relação teórico-prática com as 
comunidades, possibilitando a vivência de conteúdos curriculares estudados em sala de aula com os desafios inerentes à realidade social, portanto a extensão universitária produz inovação pedagógica ao estabelecer uma relação dialógica entre a universidade e a sociedade, ao possibilitar ao aluno uma reconfiguração de saberes e garantir seu protagonismo nesse processo. Desta forma seu papel no currículo é fundamental ao proporcionar a ecologia de saberes na extensão invertida (SANTOS, 2008).

$\mathrm{Na}$ continuidade da pesquisa nos dedicamos a analisar a contribuição da extensão universitária para a docência inovadora a partir do olhar das professoras sobre suas experiências nos projetos de extensão das Ligas do Curso de Enfermagem da Universidade Estadual Vale do Acaraú. Mantendo a abordagem qualitativa de análise, selecionamos as Ligas do Curso de Enfermagem por serem projetos contínuos de extensão, com fama de serem exitosas para os alunos e já terem uma tradição na instituição. No segundo momento entramos em contato com as cinco Coordenadoras Docentes das referidas Ligas para realização das entrevistas. O objetivo foi ouvir das docentes, por meio da entrevista semiestruturada, como elas veem a contribuição da extensão universitária para a docência e, a partir dessa visão, inferirmos as potencialidades para uma docência inovadora. As entrevistas foram gravadas e transcritas. Optamos pela análise de conteúdo com categorias previamente definidas.

\section{A contribuição das ligas da enfermagem da UVA para a docência inovadora}

As Ligas acadêmicas (LA) são conceituadas como atividades extracurriculares desenvolvidas por estudantes sob a coordenação de um orientador docente; no entanto, segundo Azevedo e Dini (2006), não existe um conceito fechado do que seja uma LA, apesar do aumento significativo do aumento de sua criação nos cursos de graduação; no caso específico de nossa pesquisa este fato é constatado no curso de Enfermagem de nossa IES, que atualmente possui cinco LA, todas nascidas fruto do protagonismo dos discente que diante da necessidade e interesse de aprofundar seus conhecimentos acerca de uma determinada área e necessidade de fortalecer o diálogo com as comunidades.

No Brasil, as primeiras experiências surgem durante o período da ditadura, com a criação da primeira liga na área de saúde no ano de 1920, a Liga de Combate à Sífilis, por iniciativa do Centro Acadêmico Oswaldo Cruz da Faculdade de Medicina da Universidade de São Paulo (MELO; BERRY; SOUSA, 2019). 
Atualmente as ligas no caso dos cursos de Enfermagem encontram amparo legal nas Diretrizes Curriculares dos Cursos de Graduação em Enfermagem através da Resolução Nacional de $\mathrm{n}^{\mathrm{o}} 3$, de 7 de novembro de 2001, que preconiza como um dos seus objetivos o aprender a aprender, que é a síntese do aprender a ser, aprender a fazer, aprender a viver juntos e aprender a conhecer.

Nesta perspectiva as atividades das ligas são fundamentais para o fortalecimento da tríade ensino, pesquisa e extensão na medida, em que possibilita aos acadêmicos desenvolverem uma reflexão sobre sua formação e atuar junto às comunidades na busca de atender suas demandas e como uma forma de dialogar e aprender na medida que ocorrem as trocas entre saberes e experiências. As Ligas Acadêmicas no Curso de Enfermagem surgem neste contexto, com os mesmos objetivos de fortalecer a formação acadêmica e o diálogo com as comunidades. Atualmente o curso possui cinco ligas, conforme quadro abaixo:

\section{Quadro 1 - Ligas Acadêmicas no Curso de Enfermagem}

\begin{tabular}{|c|c|c|}
\hline Liga & Objetivos & Público Alvo \\
\hline $\begin{array}{l}\text { Liga Interdisciplinar em } \\
\text { Saúde Mental -LISAM }\end{array}$ & $\begin{array}{l}\text { Mobilizar e orientar alunos dos cursos de } \\
\text { Enfermagem, Educação Física e Pedagogia da } \\
\text { Universidade Estadual Vale do Acaraú - UVA, } \\
\text { interessados em estudar Saúde Mental nos } \\
\text { âmbitos da pesquisa, ensino e extensão. Tem por } \\
\text { objeto de estudo uma gama de assuntos que } \\
\text { abrange a Saúde Mental. }\end{array}$ & $\begin{array}{l}\text { - Escolas } \\
\text { - Universidade } \\
\text {-Casa Acolhedora } \\
\text {-Fazenda Esperança } \\
\text { - CAPS Geral }\end{array}$ \\
\hline $\begin{array}{l}\text { Liga de Promoção à } \\
\text { Saúde do Adolescente - } \\
\text { LIPSA - }\end{array}$ & $\begin{array}{l}\text { Contribuir para a vivência dos acadêmicos de } \\
\text { enfermagem e para relação ensino-prática; } \\
\text { Promover ações educativas com adolescentes de } \\
\text { acordo com as diretrizes da Atenção Integral à } \\
\text { Saúde de Adolescentes e Jovens em diversos } \\
\text { espaços sociais. }\end{array}$ & Adolescentes \\
\hline $\begin{array}{l}\text { LENUE - Liga de } \\
\text { Enfermagem } \\
\text { Urgência e Emergência }\end{array}$ & $\begin{array}{l}\text { Promover aos acadêmicos de enfermagem a } \\
\text { oportunidade de aprofundarem seus } \\
\text { conhecimentos no âmbito da assistência de } \\
\text { enfermagem em urgência e emergência. }\end{array}$ & $\begin{array}{l}\text { Comunidade do município } \\
\text { de Sobral }\end{array}$ \\
\hline $\begin{array}{l}\text { Liga acadêmica de } \\
\text { Enfermagem em Saúde } \\
\text { da Família - LESF }\end{array}$ & $\begin{array}{l}\text { Mobilizar e orientar alunos do Curso de } \\
\text { Enfermagem interessados em estudar Saúde da } \\
\text { Família nos âmbitos da pesquisa, ensino e } \\
\text { extensão. Tem-se por objeto de estudo assuntos } \\
\text { abrangendo o Atendimento Básico e Primário; }\end{array}$ & Unidades de Saúde \\
\hline $\begin{array}{l}\text { Liga de Enfermagem em } \\
\text { Cardiologia } \\
\text { LECARDIO }\end{array}$ & $\begin{array}{l}\text { Promover aos acadêmicos de enfermagem o } \\
\text { aprofundamento teórico e prático no âmbito do } \\
\text { cuidado de enfermagem aos pacientes com } \\
\text { cardiopatias }\end{array}$ & $\begin{array}{l}\text { Hospital do Coração de } \\
\text { Sobral }\end{array}$ \\
\hline $\begin{array}{l}\text { Liga Interdisciplinar de } \\
\text { Gerontologia - LIGER }\end{array}$ & $\begin{array}{l}\text { Desenvolver conhecimentos, habilidades e } \\
\text { atitudes gerontológicas em seus integrantes para o } \\
\text { cuidado à pessoa idosa no município de Sobral }\end{array}$ & Idosos \\
\hline
\end{tabular}

Fonte: elaborado pelas autoras 
Para as professoras das ligas, que também são coordenadoras dos projetos, a extensão significa uma "ação continua, dialogada e impactante com a comunidade". Ao estabelecer uma relação interativa e reflexiva entre o que ensina, pesquisa e o que a sociedade precisa, a extensão cumpre um papel de "mão dupla" (SANTOS, 2008).

A extensão é a ação propriamente dita, [...] o ideal é que essas atividades não sejam de curto prazo, que elas tenham começo, que elas tenham desenvolvimento, e que o objetivo seja impactar aquela comunidade, [...] é de uma ação continua, dialogada e impactante para a comunidade. [...] extensão que é quando a universidade reflete esses saberes com a comunidade então é essa interação mais forte entre aquilo que a gente está estudando, entre aquilo que a gente está pesquisando, né, e a sociedade.

As docentes afirmam que o trabalho nas ligas estimula o aluno a ter "contato com o saber popular", ter "uma visão da dinâmica social com os territórios" e comprometer-se com a comunidade em que atua. Esse processo de aprendizagem desenvolve no aluno "um senso de responsabilidade social, de empatia" que vai além da dimensão técnica da enfermagem.

Identificamos nas falas das entrevistadas que a experiência com as ligas acadêmicas reflete na dinâmica da sala de aula porque "são novos aprendizados, e cada vez que você aprende você tem que levar isso pra sua prática de sala de aula [...] e quando você sai do âmbito da universidade e vai pros territórios, [...] não tem como você não chegar a sala de aula e não utilizar aquilo que você aprendeu [...]".

As docentes destacam que além do aprendizado técnico as ligas proporcionam a elas e aos discentes o contato com as pessoas, com outras formas de saberes que serão fundamentais para seu processo formativo: "Eu aprendo a lidar com gente, a extensão é exatamente isso, é lidar com pessoas, é negociação, tudo isso que não tem nos livros né”. Essas aprendizagens favorecer no bom desempenho dos alunos em sala de aula, na melhor compreensão sobre os conteúdos das disciplinas porque "[...] entendem melhor o que estão aprendendo nos livros, faz mais sentido para eles (alunos)".

A extensão universitária é vista pelas docentes como um elemento importante na construção do conhecimento do ligante, porque é o lugar em que o aluno procura se "assegurar de alguma coisa", "saber mais sobre algum tipo de doença mental", saber mais de si mesmo quando pensa "eu tô vulnerável também". Ela contribui para a construção do conhecimento a partir da experiência com responsabilidade social porque "são novos aprendizados, e cada vez que você aprende você tem que levar isso pra sua prática de sala de aula". 
As docentes destacam que os alunos que participam das ligas fortalecem habilidades, em destaque a comunicação, a identificação do problema, o diagnóstico, a escuta, desenvolvem segurança e empoderamento nas temáticas das disciplinas que elas ministram no curso de enfermagem e estabelecem uma relação com o saber popular.

\begin{abstract}
[...] as coisas que a gente mais percebe em sala de aula é o fortalecimento dessas habilidades mesmo, primeiro é a capacidade, habilidade de comunicação, todas as ações eles têm que, mesmo os mais tímidos, eles ficam com mais facilidade de chegar e de conversar, de fazer uma roda de conversa $[\ldots]$.
\end{abstract}

[...] sentem-se mais empoderados pra poder discutir a temática que eles estudaram [...], se sentem mais seguros, demonstram isso em sala de aula, então dá perfeitamente pra você perceber como é que o aluno se desenvolve quando passa por um projeto de extensão em especial das ligas, e os alunos das ligas, eles mesmo dão esse depoimento.

A experiência das ligas favorece a docência inovadora na universidade porque provoca o planejamento e o desenvolvimento de ações pedagógicas a partir das demandas das ações desenvolvidas pelas ligas de enfermagem. Favorece um planejamento dinâmico porque "você traz de volta pra dentro da sala de aula pra discutir no seu curso, pra discutir com os seus professores com aqueles saberes, e também pra pesquisar né”.

A experiência e o saber que dela deriva são os que nos permitem apropriar-nos de nossa própria vida. Compreendemos que a extensão universitária é um espaço que reivindica o saber da experiência como saber fundante da docência inovadora e de tudo que dela deriva. Bodia (2002) sugere a experiência como um acontecimento que nos toca, nos acontece. O saber originário dessa experiência é fruto da relação entre o conhecimento e a vida humana. É uma espécie de mediação entre ambos. Por isso, o saber da experiência é, na perspectiva desse autor, um saber particular, subjetivo, relativo, contingente e pessoal.

Nesse sentido a extensão universitária, para os alunos, para as docentes e também para a comunidade, pode ser um acontecimento de múltiplos saberes originados dos múltiplos sentidos do que pode acontecer. A fala das entrevistadas nos revela que experiência das ligas acadêmicas coloca o aluno e a professora na condição de vulnerabilidade epistemológica, onde o saber é finito, ligado à existência de um indivíduo ou de uma comunidade humana particular.

A partir das falas das entrevistadas, evidenciamos forte papel das ligas em proporcionar uma experiência em que o diagnóstico não se sustenta somente no saber técnico, mas na escuta qualificada do saber popular e da comunicação dialógica (FREIRE, 1977) que as comunidades evocam. $\mathrm{O}$ compromisso de mudança estabelecido nas experiências das ligas 
é selado numa relação de horizontalidade e de respeito à cultura local entre universidade e sociedade.

Contribuindo com a reelaboração da prática docente a partir dos novos aprendizados adquiridos nos territórios, as ligas provocam o exercício de uma docência reiventiva nos processos pedagógicos porque se abrem para novos percursos formativos demandados pelos alunos e pela comunidade. Nesse contexto que a docência inovadora pode acontecer, pois as experiências reinventivas de ensinar e aprender são construídas nas novas formas de sociabilidades, novas formas de se comunicar e se relacionar. Formas de inventar-se e reinventar-se. Nesse movimento de inventar e reiventar-se que a "inventabilidade da diferença" (HALL, 2011) acontece.

$\mathrm{O}$ ato de invertar-se e reinventar-se na docência é um ato político para enfraquecer as hierarquias epistemológicas da racionalidade técnica, científica e instrumental que estruturam os currículos universitários e fortalecer as identidades fronteiriças. O currículo, por ser uma razão particular, historicamente formado para organizar o conhecimento como formas de regulação social, produzidas através de estilos privilegiados de raciocínio (POPKEWITZ, 1997), necessita de uma docência capaz de encontrar fugas que tencionem o "conhecimento corporificado em formas particulares de agir, sentir, falar e ver o mundo e o 'eu'" (POPKEWITZ, 2001, p. 176), para abrir outras formas de agir, sentir, falar e ver o mundo e outros 'eu'. Portanto, a docência inovadora sempre é intencional e carrega o ônus da complexidade da iniciativa, pois pressupõe um pensamento pedagógico transformador.

Neste cenário, a docência universitária é afetada e transformada a partir das experiências e aprendizados realizados com o contato com essas novas formas de conceber e fazer ciência à medida que provoca um repensar de sua atuação em sala.

Cunha (2005) indica a docência universitária inovadora como "um processo de ruptura de paradigmas no cotidiano da prática pedagógica universitária" que enseja o protagonismo docente, ou seja, da "consideração de que o professor é o agente principal das decisões e ações no campo" (CUNHA, 2005, p. 107). A docência universitária inovadora é concebida como um movimento intencional que visa produzir novas formas e espaços educativos. Ela mobiliza saberes e conhecimentos no âmbito do currículo, das formas de ensinar e aprender, no ensino e na pesquisa.

A docência inovadora é compreendida aqui como "uma atitude epistemológica do conhecimento para além das regularidades propostas pela modernidade" (MOROSINI, 2006, p. 445). Opondo-se à tendência utilitarista de inovação do discurso empresarial sobre educação, a inovação na docência funda-se pela ruptura paradigmática (CUNHA, 2005) e 
pelo protagonismo na gestão e desenvolvimento da prática pedagógica por parte, principalmente, dos professores (LUCARELLI, 2007). A ruptura paradigmática implica romper com padrões e modelos pré-estabelecidos de ensino-aprendizagem, ensejando novas formas de comportamento que passam a ser alimentadas por mecanismos de resistência, singularidade, diferenciação e oposição nos processos educativos.

\section{Considerações finais}

Compreendemos que a extensão estabelece uma relação teórica e prática com as comunidades, possibilitando a vivência de conteúdos curriculares estudados em sala de aula com os desafios inerentes à realidade social. Consideramos a extensão universitária como uma inovação pedagógica por estabelecer uma relação dialógica entre a universidade e a sociedade, por meio do protagonismo estudantil, da reconfiguração dos saberes, da descolonização dos currículos, das práticas reinventivas da docência e da democratização epistemológica na universidade.

Com base nas falas das entrevistadas concluímos que as ligas de enfermagem contribuem para uma docência inovadora porque permitem:

a) a participação ativa e protagonista do aluno, possibilitando-o desenvolvimento da capacidade crítica, criatividade e propositiva;

b) um movimento ecológico de saberes: científicos, profissionais, tecnológicos e de experiência;

c) uma relação mediadora na diversidade cultural existente entre docente, discente e comunidade;

d) gerar a necessidade de recriação dos caminhos curriculares para os processos formativos;

e) a produção de conhecimento científico com responsabilidade social e ética.

f) repensar o planejamento das disciplinas a partir das demandas trazidas pelos alunos no exercício da extensão.

g) reflexões sobre os processos de ensino-aprendizagem na sala de aula universitária.

A extensão universitária via ligas acadêmicas da enfermagem na Universidade Vale do Acaraú favorece uma docência inovadora porque a desafia a promover uma aprendizagem criativa, humana e contextualizada, fortalecendo valores como compromisso, empatia e 
sensibilidade, retroalimentação de saberes necessários para uma relação de respeito e valorização das experiências advindas dos territórios onde as ligas atuam.

\section{REFERÊNCIAS}

AZEVEDO, R. P.; DINI, P. I. Guia para construção de ligas acadêmicas [Internet]. Assessoria Científica da Direção Executiva Nacional dos Estudantes de Medicina, 2006. Disponível em: http:// www.daab.org.br/texto.asp?registro=157. Acesso em: 01 nov. 2019.

BONDÍA LARROSA, J. Notas sobre a experiência e o saber de experiência. Revista Brasileira de Educação [en linea], n. 19, p. 20-28, jan./abr. 2002. ISSN 1413-2478. Disponível em: http://www.redalyc.org/articulo.oa?id=27501903. 01 Acesso em: nov. 2019.

BRASIL. Conselho Nacional de Educação. Parecer Homologado - Portaria n. 1.350. Diretrizes para Políticas de Extensão da Educação Superior Brasileira. Diário Oficial da União, Brasília, 17 dez. 2018, Seção 1, p. 34.

BRASIL. Lei n. 13.005, de 25 de junho de 2014. Aprova o Plano Nacional de Educação (PNE) e dá outras providências. Diário Oficial da União, Brasília, 26 jun. 2014.

CAMPANI, A.; SILVA, R. M. G.; PARENTE, P. M. M. Inovação Pedagógica na Universidade. Revista Educação e Fronteiras On-Line, v. 8, p. 18-34, 2018.

CUNHA, M. I. A docência como ação complexa. In: CUNHA, M. I. (Org.). Trajetórias e lugares de formação da docência universitária: da perspectiva individual ao espaço institucional. Araraquara, SP: Junqueira \& Marin; Brasília: CAPES; CNPq, 2010.

CUNHA, M. I. O professor universitário na transição de paradigmas. 2. ed. Araraquara: Junqueira \& Marin editores, 2005.

CUNHA, M. I. Pedagogia Universitária. In: MOROSINI, M. C. (Org). Enciclopédia de Pedagogia Universitária: Glossário. v. 2. Porto Alegre: INEP/RIES, 2006.

FREIRE, P. Extensão ou comunicação. 10 ed. Trad. Rosisca Darcy de Oliveira. Rio de Janeiro: Paz e Terra, 1977.

HALL, S. A identidade cultural na pós-modernidade. Trad. Tomás Tadeu da Silva e Guacira Lopes Louro. 11. ed. Rio de Janeiro: DP\&A,2001.

IMBERNÓN, F. (Org.) A educação do século XXI. Porto Alegre, RS: Artmed, 2000.

LUCARELLI, E. Pedagogia universitária e inovação. In: CUNHA, M, I. (Org.) Reflexões e práticas em pedagógica universitária. Campinas: Papirus, 2007. p. 11-26.

MELO, T. S. de; BERRY, M. C.; SOUZA, M. I. Ligas acadêmicas de odontologia: uma revisão de literatura. Revista da ABENO, v. 19, n. 1, p.10-19, 2019. Disponível em: https://revabeno.emnuvens.com.br/revabeno/article/download/635/519. Acesso em: 01 nov. 2019. 
MOROSINI, M. C. (Org). Enciclopédia de Pedagogia Universitária: Glossário. v. 2. Porto Alegre: INEP/RIES, 2006.

POPKEWITZ, T. Reforma educacional: uma política sociológica poder e conhecimento em educação. Porto Alegre: Artes Médicas, 1997.

POPKEWITZ, T. S. Lutando em defesa da alma: a política do ensino e a construção do professor. Trad. Magda França Lopes. Porto Alegre: Artmed Editora Ltda., 2001.

SANTOS, B de S. Universidade do século XXI: para uma reforma democrática e emancipatória da universidade. 3. ed. São Paulo: Cortez, 2011.

SANTOS, B. S; ALMEIDA FILHO, N. A Universidade no século XXI: para uma Universidade Nova. Coimbra: Edições Almedina, 2008.

SILVA, R. M. G.; CAMPANI, A.; PARENTE, P. M. M. A extensão universitária como pilar epistemológico da indissociabilidade na universidade. In: HOLANDA, V. C. C.; SILVA, R. M. G. da (Orgs.). A expansão do ensino superior em debate. 1. ed. Sobral: Edições UVA, 2018. p. 95-110.

UNIVERSIDADE ESTADUAL VALE DO CARAU - UVA. Resolução n. 27/2018 -

CEPE. Dispõe Sobre A Curricularização da Extensão nos Cursos de Graduação da Fundação Universidade Estadual Vale do Acaraú (UVA). Sobral, 2018. Disponível:

http://www.uvanet.br/documentos/resolucao_ca4e1e77fe6b72081c9e64cba8bd3386.pdf.

Acesso em: 02 nov. 2019.

UVA. Plano Organizacional da Universidade Estadual Vale do Acaraú: 2008-2012.

Sobral: Edições Universitárias,2008

\section{Como referenciar este artigo}

CAMPANI, A.; SILVA, R. M. G. da.; NEGREIROS, J. G. Contribuição da extensão para uma docência universitária inovadora: um estudo a partir do programa de Ligas da Enfermagem da Universidade Estadual Vale do Acaraú. Revista Ibero-Americana de Estudos em Educação, Araraquara, v. 15, n. esp. 2, p. 1615-1628, ago. 2020. e-ISSN: 19825587. DOI: https://doi.org/10.21723/riaee.v15iesp2.13835

Submetido em: 30/08/2019

Revisões requeridas: $30 / 11 / 2019$

Aprovado em: 02/02/2020

Publicado em: 01/08/2020 